\title{
SOBRE EL PAPEL DEL JUEZ NACIONAL EN LA APLICACIÓN DEL DERECHO EUROPEO Y SU CONTROL
}

\author{
Luis Martín Rebollo \\ Catedrático de Derecho Administrativo \\ Universidad de Cantabria
}

\begin{abstract}
RESUMEN
En el presente artículo se analiza el papel de los jueces nacionales en la aplicación del derecho de la Unión Europea poniendo énfasis en la jurisprudencia del Tribunal Constitucional y, a partir de ella, describiendo la cambiante doctrina acerca de los supuestos en los que los jueces pueden inaplicar una ley nacional por entenderla contraria al derecho de la Unión Europea o a la jurisprudencia de Luxemburgo, con referencia también a la incidencia en este tema de la nueva regulación del recurso de casación.
\end{abstract}

Palabras clave: cuestión prejudicial; inaplicación de leyes nacionales; recurso de casación; relaciones Tribunal Constitucional-Tribunal de Justicia de la UE.

\begin{abstract}
This article analizes the role of national judges in the enforcement of European Union Law with special reference to the doctrine of the Constitutional Court and to the changes regarding cases in which judges must put the "prejudicial question» to the Court of EU Law in Luxemburg. As well as that, the study deals with the circumstances in which it is not necessary to put the "prejudicial question" and the judges can disapply national Law in some concret and specific cases. There is also a reference to the new judicial procedure of «cassation».
\end{abstract}

Key words: role of national judges in European Law; prejudicial question; inapplicability of national Law; judicial procedure of «cassation». 
1.- La entrada de España en la actual Unión Europea el 1 de enero de 1986 fue la culminación de un largo proceso que se inicia en 1962, todavía en pleno período franquista al albur de los procesos de apertura económica que significa el llamado Plan de Estabilización, y termina como una especie de culminación de la transición política a la democracia en junio de 1985 con el Tratado de Adhesión y la efectiva incorporación a las instituciones europeas a partir, como digo, del 1 de enero de 1986.

Este simple dato, que es el que se suele citar, no da cumplida cuenta, sin embargo, del significado real del ingreso de España en la entonces Comunidad Económica Europea. A partir de ese momento, sí, comienza el complejo proceso de incorporar al derecho interno español todo el acervo comunitario, esto es, el conjunto de normas y principios existentes en la Comunidad que eran eso, normas, que había que trasponer, pero también principios, que había que ir asumiendo en el tejido colectivo. Si incorporar los primeros no era tarea fácil, parémonos un momento a pensar en lo difícil que era y sigue siendo asumir los principios porque detrás de ellos hay algo más que las tradiciones constitucionales comunes a los Estados miembros, como suelen repetir los Tratados fundacionales. Detrás de los principios hay una historia turbulenta que se pretende superar, unos valores que se tienen que asumir, una cultura del acuerdo que tiene que penetrar en todos los intersticios de la sociedad donde resultaba y resulta fundamental el papel de algunos operadores sociales, en particular la prensa, la escuela y los tribunales.

A mi juicio, y valorando en su conjunto estos treinta años de pertenencia a Europa, se puede decir que España pasa por un periodo inicial de entusiasta —y comprensible — europeísmo a un período — el actual— menos entusiasta cuando a la crisis institucional europea se une la crisis económica, política y social española y la mirada a Europa no devuelve soluciones milagrosas porque Europa ya no son «ellos» sino que también somos «nosotros». No obstante, no se debe olvidar los enormes beneficios que a España le ha proporcionado la entrada en la Unión; beneficios contables y tangibles, además de otros quizá menos tangibles y contables, y que no siempre los medios se han encargado de airear. En particular, hay que recordar, aunque ello suponga desviarme un poco del objetivo de este breve ensayo, las ayudas recibidas de los Fondos Europeos; ayudas de las que se han beneficiado, de una u otra manera, con cargo a uno u otro "Objetivo», todas las comunidades autónomas. Así, en los primeros quince años en torno al 80 por ciento del territorio español que representaba en su conjunto a un 60 por ciento de la población se benefició de ayudas directas que contribuyeron sustancialmente a elevar el nivel medio de renta desde el 64 por ciento inicial de la media de 
la UE hasta el 81 por ciento en relativamente pocos años. La mejora del sistema productivo en la industria, el turismo, la agricultura, la pesca o el I+D; el aumento de la calidad de vida en el ámbito de la educación, la sanidad y el medio ambiente; el desarrollo de las comunicaciones (carreteras, vías férreas, puertos, aeropuertos) y otros equipamientos en materia de agua o energía fueron logros conseguidos - ciertamente antes de la crisis- gracias a las decenas de miles de millones de euros; en realidad, más de 100.000 millones de euros, esto es, casi 20 billones de las antiguas pesetas. Sí, unas cifras astronómicas impensables e inalcanzables para una frágil economía que llegó a tener un 27 por ciento de inflación y en la que precio del dinero para los afortunados que podían obtener un crédito hipotecario se llegó a situar en esa época inicial de los años ochenta en el 15 y el 16 por ciento.

Con parte de ese dinero que venía en abundancia de Europa - y que no siempre se acertó a usar y mucho menos a explicar de dónde, cómo y por qué venía - se financiaron parcialmente proyectos que hoy son realidades tangibles como varias líneas del AVE, autovías, obras de saneamiento y depuración de aguas de varias ciudades, proyectos de gestión de residuos urbanos, no pocos edificios universitarios y un muy largo etcétera.

He ahí, pues, una perspectiva de la que no se habla mucho cuando se alude al euroescepticismo, pero que debería considerarse también desde la óptica de la vida cotidiana y de los beneficios que la entrada en la Unión han supuesto para España; beneficios de los que ahora se tendrán que aprovechar más otros países que están en condiciones similares o peores a las que estábamos nosotros hace ahora treinta años.

Pero no es sólo la importante inyección que para nuestro progreso supuso la entrada en la Unión Europea. Hubo otros factores adicionales no menos destacados. Entre ellos, lo que significó la ruptura de fronteras, la libre circulación de personas, mercancías y capitales, la libertad de establecimiento o los numerosos programas de acción y, entre ellos, de forma destacada, el importantísimo Programa Erasmus (cuya impulsora, la profesora Sofía Corradi, ha recibido el pasado mes de mayo el Premio Europeo Carlos V, de la Fundación Academia Europea de Yuste) que ha permitido el hasta hace poco impensable fenómeno de que miles de jóvenes universitarios completen un año de su formación fuera de su país para aprender no tanto técnicas o conocimientos precisos -aunque también - sino, sobre todo, impregnarse de aires nuevos, de talantes distintos, de la pluralidad que supone el gran caleidoscopio europeo.

Así, pues, la integración en las instituciones europeas fue un acontecimiento de primer orden y una realidad a la que dos de los operadores 
sociales a los que hace un momento me refería no siempre han dedicado suficiente atención divulgativa o, cuando lo han hecho, han puesto a veces más el acento en las disfunciones — que también las ha habido, es cierto- o en la superficialidad de las cosas. Me refiero, claro está, a los medios y a la escuela. Los medios tienen un valor incalculable a la hora de airear las disfunciones, como la realidad demuestra, pero tienen también la responsabilidad de explicar los logros positivos. La escuela, por su parte, debería ser el lugar donde socializar los valores europeos que son también algunos de los valores que hoy lucen en el frontispicio de nuestra Constitución. Pues bien, al cerrar este primer apartado introductorio permítaseme un cierto escepticismo acerca de esa labor social de integrar los valores europeos; escepticismo que incluye también, por supuesto, la autocrítica de lo que nos afecta e incumbe a nosotros, los profesores universitarios...

2.-El tercer elemento de socialización de los valores europeos es el derecho en general y su aplicación particular, en lo concreto, donde el papel del juez resulta fundamental. Su papel consiste en aplicar el derecho pero también contribuir a garantizar una característica clave del derecho europeo, a saber, que sea verdaderamente el derecho de prioritaria aplicación, el derecho común que prima sobre los derechos nacionales cuando ambos se oponen y que con su aplicación unitaria y homogénea coadyuva a la consolidación de un cuerpo doctrinal de aplicación general en todos los países de la Unión. Una tarea esencial, la más esencial quizá en la construcción europea. No es una afirmación gratuita la que acabo de hacer. Porque el derecho contribuye a diseñar la estructura social, a consolidar institucionalmente el edificio que construye la voluntad política, a confirmar derechos y garantías comúnmente aceptadas. ¿Cómo afrontar esa tarea esencial?, ¿cómo utilizar las herramientas que las instituciones ponen a su servicio?, ¿cuáles son esas herramientas?

La primera tarea que se autoimpuso el legislador español tras la entrada de nuestro país en la Comunidad fue modificar la legislación española que se necesitaba por resultar opuesta o no compatible con el «background» comunitario. Se aprobó así la Ley 47/1985, de 27 de diciembre, de Bases de delegación al Gobierno para la aplicación del derecho de las Comunidades Europeas. En esa Ley y a efectos del art. 82 de la Constitución se consideran bases, principios y criterios de la delegación los textos de «las Directivas y demás normas de derecho comunitario cuya aplicación exija la promulgación de normas internas con rango de Ley» (art. 2). Y en el Anexo de la Ley se enumeraba una larga lista de 36 leyes afectadas que había que modificar y más de 70 Directivas que había que incorporar. 
Se cumplía así, como digo, la primera tarea que en el plano jurídico implicaba al Estado: garantizar la adecuación de su propio derecho interno a los postulados comunes del derecho europeo. De manera que una vez terminado ese primer y complejo trabajo y puestas las bases para que en adelante todas las normas internas se aprobaran tras superar el «test» de su adecuación al derecho de la Unión, surgió una segunda tarea no menos importante: la de aplicar el derecho europeo con carácter prevalente puesto que, como ya entonces había señalado la jurisprudencia del Tribunal de Justicia de Luxemburgo, el principio de primacía del derecho comunitario es un principio esencial de este derecho que resulta inherente a la propia naturaleza de la Unión. De hecho, se trata de un principio que no está explícitamente contemplado en los Tratados (se pretendía incluirlo en la llamada "Constitución» para Europa), pero ese dato omisivo no afecta a su operatividad que, como digo, es un principio que está estrechamente vinculado al basamento jurídico e institucional de la Unión, de manera que si una norma interna, cualquiera que sea, pudiera superponerse a la normativa comunitaria, ésta perdería su carácter común y se pondría en cuestión la propia base jurídica de la Unión.

Y ahí es donde aparece el juez, el tercer operador responsable de la unidad del derecho; un elemento poco lucido o de presencia oscura, pero un elemento absolutamente esencial en la construcción europea. Porque esa tarea de aplicar y hacer aplicar el derecho comunitario corresponde en el ámbito de sus respectivas competencias a los jueces nacionales, a todos los jueces nacionales. Son ellos los jueces del derecho europeo y por eso los particulares pueden también alegar ante ellos la invalidez de una disposición europea (así, STJCE de 11 de noviembre de 1997). Su tarea última es garantizar la aplicación común del derecho europeo y eso exige una interpretación igualmente común, lo que nos lleva a la pregunta central: ¿cómo conseguir esa interpretación unificada?

La respuesta, como es bien sabido, la da el propio Tratado fundacional. Según el art. 267 del TFUE los jueces nacionales pueden plantear cuestiones prejudiciales al Tribunal de Justicia sobre la interpretación del Tratado o sobre la validez e interpretación de las normas del derecho derivado en relación con el derecho originario (los Tratados) que hayan de aplicar cuando tengan que hacerlo.

Y ahí surge una larga y compleja polémica acerca de los poderes del juez nacional y los supuestos en los que debe o puede plantear la cuestión prejudicial; una polémica que ha tenido y tiene altibajos, interpretaciones no siempre coincidentes entre los tribunales nacionales -incluidos los Tribunales Constitucionales- y el Tribunal de Justicia 
de la Unión. Trataré en este artículo de exponer, sin ninguna pretensión de originalidad, algunos de los hitos o pautas de inflexión de esa polémica que se prolonga en el tiempo y está seguramente aún lejos de parecer cerrada.

Se trata de una polémica que, más allá de sus aspectos técnicos y procesales que pueden oscurecer el verdadero problema, suscita un debate de interés sobre la propia Unión y la posición de los jueces nacionales en la medida en que, en efecto, lo que se suscita en el fondo es la consideración inequívoca del juez nacional como juez del sistema judicial europeo, de la misma manera que el legislador o las Administraciones internas forman parte del sistema político y administrativo europeo en lo que concierne al ámbito de las materias en las que la Unión posee competencias. $\mathrm{O}$, dicho de otra manera, hay que observar esta cuestión más allá de sus inevitables aspectos técnicos para destacar que lo que subyace en la polémica es, como digo, la consideración de un espacio judicial europeo al servicio del propio derecho europeo y de su interpretación homogénea y común. Una tarea hercúlea, desde luego, para la que se precisan al menos dos cosas: un conocimiento razonablemente preciso del derecho europeo y aun de la jurisprudencia del Tribunal de Justicia y, además, unas reglas razonablemente claras acerca de las dos cuestiones más importantes implicadas: cuándo el juez tiene o puede plantear la cuestión prejudicial y cuando puede simplemente inaplicar la norma interna dando prioridad al derecho europeo sin necesidad de plantear la cuestión para no colapsar el Tribunal y hacer inviable — por éxito- el objetivo unificador pretendido.

La primera cuestión —el conocimiento del derecho europeo- apela a aspectos que aquí no procede analizar pero que tienen que ver con la definitiva asunción de que el derecho de la Unión es también a todos los efectos derecho español. Y eso se tiene que traducir en los planes de estudio, en los temarios de las oposiciones, en los cursos de especialización. El segundo tema - los supuestos en los que procede o no la cuestión prejudicial - afecta más directamente el objeto de estas esquemáticas páginas.

3.-La cuestión de cuándo el juez nacional puede o debe plantear la cuestión prejudicial es una cuestión que, en principio, resulta relativamente clara desde la óptica del derecho de la Unión. El juez, si duda de la adecuación de la norma que tiene que aplicar al derecho de la Unión, puede plantear la cuestión al Tribunal de Justicia de Luxemburgo. Pero puede también inaplicar la norma interna -incluso si es una ley- cuando entienda que esa norma es claramente contraria al derecho de la Unión. Si ese juez es un juez en el que se agotan las instancias 
ordinarias en el asunto de que se trate, en las mismas circunstancias dudosas no sólo puede sino debe plantear la cuestión prejudicial.

Esta es, en síntesis, la doctrina que se deriva del precepto que regula la cuestión prejudicial, el actual art. 267 del TFUE, que dice así:

El Tribunal de Justicia de la Unión Europea será competente para pronunciarse, con carácter prejudicial:

a) Sobre la interpretación de los Tratados;

b) sobre la validez e interpretación de los actos adoptados por las instituciones, órganos u organismos de la Unión;

Cuando se plantee una cuestión de esta naturaleza ante un órgano jurisdiccional de uno de los Estados miembros, dicho órgano podrá pedir al Tribunal que se pronuncie sobre la misma, si estima necesaria una decisión al respecto para poder emitir su fallo.

Cuando se plantee una cuestión de este tipo en un asunto pendiente ante un órgano jurisdiccional nacional, cuyas decisiones no sean susceptibles de ulterior recurso judicial de Derecho interno, dicho órgano estará obligado a someter la cuestión al Tribunal.

Cuando se plantee una cuestión de este tipo en un asunto pendiente ante un órgano jurisdiccional nacional en relación con una persona privada de libertad, el Tribunal de Justicia de la Unión Europea se pronunciará con la mayor brevedad.

Prescindiendo del inciso final, que procede del Tratado de Lisboa, la regulación de la cuestión prejudicial se ha mantenido igual desde el principio por más que los problemas que ha generado su interpretación hayan variado con el tiempo. En todo caso, se trata de un instituto central para garantizar, como dije, la unidad del ordenamiento europeo; unidad que no puede ser sólo normativa sino que ha de ser también y sobre todo interpretativa, que es la función principal de la cuestión prejudicial, aunque pueda hacerse algún distingo, del que ahora prescindo, entre cuestión interpretativa y cuestión sobre la validez del derecho derivado, según apunta la letra b) del art. 267.

El art. 267 ha dado lugar, a su vez, a no pocas dudas interpretativas de carácter secundario que aquí vamos a obviar. Así, se ha planteado qué hay que entender por «órgano jurisdiccional», cómo hay que considerar la expresión «decisión no susceptible de ulterior recurso judicial de Derecho interno", qué vinculación debe existir entre la duda planteada y la necesidad de solventarla para emitir un fallo o incluso qué tipo de duda (duda «razonable») debe tener el juez para poder plantear la cuestión al Tribunal de Justicia. 
4.-Las cuestiones más interesantes, a nuestros efectos, hacen referencia, a mi juicio, a tres órdenes de cuestiones: el papel general del Tribunal Constitucional en este contexto del derecho europeo, la eventual coexistencia en el ámbito interno y respecto del mismo asunto de dudas de inconstitucionalidad de la norma a aplicar y, al tiempo, de similares dudas de adecuación al derecho de la Unión y, sobre todo, el problema central de saber cuándo un Tribunal que, en principio, debe plantear la cuestión puede estar eximido de ello y decidir por sí mismo dar prioridad al derecho europeo y, en consecuencia, inaplicar una norma interna; aspecto este que tendría menor importancia si la norma interna fuera un simple reglamento porque esa posibilidad ya existe ex art. 6 LOPJ, pero que adquiere una relevante y aun esencial importancia cuando se trate de una norma con rango y fuerza de ley, lo que exige un acercamiento cuando menos prudente a tema tan delicado.

Me referiré brevemente y por separado a estas cuestiones.

a) Por lo que hace al Tribunal Constitucional su posición ha sido tradicionalmente reacia a convertirse en juez del derecho europeo. Es decir, a considerar como parámetro de la constitucionalidad a las normas del derecho de la Unión Europea. Ese posicionamiento ha sido constante desde el principio y de él puede ser buena muestra la reciente Sentencia 215/2014, de 18 diciembre, que lo sintetiza. En su Fundamento Jurídico tercero la Sentencia recuerda que desde la incorporación de España a las Comunidades Europeas «se integró en el ordenamiento español un sistema normativo autónomo, dotado de un régimen de aplicabilidad específico, basado en el principio de prevalencia de sus disposiciones propias frente a cualesquiera del orden interno con las que pudieran entrar en contradicción». Las normas de la Unión priman, sin duda, sobre el derecho nacional y — añade_ « «tienen capacidad de desplazar a otras en virtud de su aplicación preferente o prevalente», poseen un «efecto vinculante» y esa vinculación es «el fundamento último de nuestra incorporación al proceso de integración europea y de nuestra vinculación al derecho comunitario» (STC 100/2012, de 8 de mayo). Sin embargo -y aquí radica la cuestión central—, eso «no significa que por mor del art. 93 se haya dotado a las normas del derecho comunitario europeo de rango y fuerza constitucionales». Y cita al respecto numerosas sentencias anteriores, entre ellas las SSTC 28/1991, de 14 febrero; 64/1991, de 22 marzo; y 134/2011, de 20 julio. Y tampoco supone que el derecho comunitario, ya sea el derecho originario, ya el derivado, constituya canon de la constitucionalidad de las normas con rango de ley (SSTC 235/2000, de 5 octubre; 12/2008, de 29 enero; y 136/2011, de 13 septiembre). 
La posición es clara aunque pueden, quizá, adivinarse algunas quiebras en un doble orden de consideraciones. Por un lado, el Tribunal Constitucional, después de haberlo negado explícitamente (STC 28/1991, de 14 febrero), aceptó finalmente la posibilidad de plantear él mismo una cuestión prejudicial al Tribunal de Luxemburgo. En el llamado Caso Melloni (un caso de extradición que afectaba a la interpretación de la Carta de Derechos Fundamentales), el TC, mediante Auto 86/2011, de 9 junio, planteó una cuestión prejudicial con tres concretas preguntas que fueron contestadas en la STJ de la Unión Europea de 26 de febrero 2013, tras la que el TC español desestimó el amparo planteado por el Sr. MELLONI (STC 26/2014, de 13 febrero). Más allá de las significativas y peculiares circunstancias del caso, que afectaba al estandar de protección de los derechos fundamentales, el mero hecho de plantear la cuestión prejudicial cuando antes el TC se había negado a ello, supone un avance en el llamado «diálogo de tribunales», como apunta el voto particular discrepante al Auto 86/2011 del magistrado Pérez Tremps, partidario de no plantear la cuestión y resolver directamente. Y, aún más, podría sostenerse que supone indirectamente aceptar como parámetro de referencia para la interpretación del derecho interno por parte del Tribunal Constitucional las pautas del derecho europeo interpretado por el TJ. El caso es muy específico porque afecta a derechos fundamentales pero en términos abstractos no es una cuestión irrelevante. Se estaría dando un (pequeño o no tan pequeño) paso en la línea de "constitucionalizar», valga el barbarismo, el papel del Tribunal de Justicia de Luxemburgo a la hora de aplicar e interpretar el derecho interno por parte del Tribunal Constitucional. Una línea simplemente esbozada que me parece interesante por más que no es esta apresurada reflexión el lugar para poder explorar sus posibilidades.

La segunda línea de tendencia del propio TC se apunta en la aún más reciente Sentencia 232/2015, de 5 noviembre, en un recurso de amparo al que luego me volveré a referir. En dicha Sentencia el TC dirá que el hecho de que las normas de la Unión Europea no tengan «rango y fuerza constitucionales» no significa que él mismo deba abstenerse «de cualquier valoración sobre un acto de los poderes públicos ante él recurrido cuando el mismo aplica derecho de la Unión Europea o, al contrario, se plantee su posible contradicción con éste, pues ello implicaría una abdicación de nuestra función señalada en los arts. 53.2 y 161.1 b) CE». Significa — precisa- que "cuando ello sucede debemos abordar esa denuncia desde la perspectiva que nos es propia, valorando si con ese acto de los poderes públicos recurrido ante la jurisdicción constitucional se ha ocasionado o no alguna vulneración a los derechos fundamentales y libertades públicas cuya tutela tenemos encomendada, de conformidad 
con los preceptos constitucionales antes citados, que son los únicos que vinculan a este Tribunal». Desde esta perspectiva, la jurisdicción constitucional debe operar con un doble canon de enjuiciamiento, que la Sentencia enuncia así: a) por un lado, el general del derecho a la tutela judicial efectiva y b) de otra parte, desde el análisis de una derivación más específica del derecho a un proceso con todas las garantías, del que formaría parte «el derecho a que los jueces y tribunales resuelvan "conforme al sistema de fuentes establecido"». Y ese sistema de fuentes incluye, claro está, el derecho de la Unión. Obviamente ese derecho prima sobre el derecho interno de modo que su desconocimiento o inaplicación supone o puede suponer una violación del art. $24 \mathrm{CE}$ en el sentido que acaba de exponerse.

Ciertamente, el TC excluye de forma directa el derecho europeo del parámetro de la constitucionalidad, pero de manera indirecta lo acepta para solventar el amparo planteado en la medida en que dicho derecho no se haya considerado aplicable y no se haya aplicado en las fases procesales previas. Es una cuestión de matiz y aun de matiz importante, pero el mero hecho de explicitarlo así está implícitamente abriendo la puerta a una aceptación explícita del derecho europeo como canon de la constitucionalidad como lo es, en otro sentido, un derecho derivado de la propia Constitución, el contenido en los Estatutos de autonomía de las comunidades autónomas.

Queden en todo caso estos dos aspectos de un proceso que no ha hecho más que empezar y en el que aún no se avizoran líneas precisas, aunque quizá sí inseguras tendencias.

b) La cuestión de la eventual coexistencia en el ámbito interno y respecto del mismo asunto de dudas de inconstitucionalidad de la norma a aplicar y, al tiempo, de similares dudas de adecuación al derecho de la Unión ha sido resuelta de manera contundente por el TJ de la UE. Se trata de los posibles supuestos de la doble contradicción, es decir, aquellos en los que la ley nacional aplicable se considere contraria tanto a la Constitución como al derecho de la UE. En tales casos, ¿puede el juez plantear la cuestión prejudicial o debe, antes, utilizar el mecanismo de control de la constitucionalidad (en España, la cuestión de inconstitucionalidad)? La respuesta la dio, de forma contundente, como digo, la STJ de 22 de junio 2010 (caso Melki). Allí, el TJ vino a decir que una norma interna que obligara a ese procedimiento en detrimento de la cuestión prejudicial sería contraria al derecho de la Unión. Así, pues, también en esos casos el juez puede plantear la cuestión prejudicial, con independencia de las previsiones del derecho interno. 
c) Se llega así al tercer aspecto al que antes me refería, al problema de saber cuándo el Tribunal que debe o puede plantear la cuestión prejudicial puede estar eximido de ello y decidir por sí mismo dar prioridad al derecho europeo y, en consecuencia, inaplicar la ley interna. Un tema importante y que, como dije, creo que hay que abordar excluyendo algunos maximalismos derivados del análisis estrictamente lógico y manejarlo con cierta prudencia por sus eventuales derivaciones prácticas.

El punto de partida es la doctrina del llamado caso Cilfit (STJ de 6 de octubre 1982). Según dicha Sentencia los órganos jurisdiccionales que están obligados a plantear la cuestión prejudicial en caso de dudas razonables acerca de la compatibilidad de la ley que tienen que aplicar con el derecho europeo estarían exentos de hacerlo y podrían inaplicar la ley interna dando prioridad al derecho europeo cuando la aplicación de dicho derecho puede imponerse con tal evidencia que no deje lugar a ninguna duda razonable. Es la llamada doctrina del «acto claro», que el TJ somete a tal cúmulo de cautelas y exigencias adicionales que, de aplicarse rígidamente, resultarían en la práctica imposibles de cumplir. De ahí que esas exigencias empiecen a relajarse un tanto en la última década sin que pueda decirse que hay ya una doctrina consolidada al respecto.

Junto a la citada «doctrina del acto claro», en la misma Sentencia aparece la también denominada «doctrina del acto aclarado», más fácil de discernir. Según dicha doctrina, cualquier órgano jurisdiccional —no sólo, pues, los que al agotar las instancias internas tienen la obligación de plantear la cuestión prejudicial en caso de dudas razonables_-, cualquier órgano jurisdiccional, digo, puede inaplicar una ley nacional sin plantear la cuestión prejudicial cuando el Tribunal de Justicia de la UE se haya pronunciado ya en un caso similar, aunque no necesariamente idéntico. Pueden inaplicar el derecho nacional, dice el TJ, aunque también pueden plantear la cuestión prejudicial si entienden que con ello aclaran aspectos aún dudosos del conflicto.

Esa es igualmente la conclusión en el ámbito interno de la antes mencionada STC 232/2015, de 5 noviembre, donde se afirma que la obligación de plantear la cuestión prejudicial desaparece aun tratándose de decisiones de órganos jurisdiccionales nacionales que no son susceptibles de un recurso judicial conforme al derecho interno, tanto cuando la cuestión planteada fuese materialmente idéntica a otra que haya sido objeto de una decisión prejudicial en caso análogo (doctrina del acto aclarado) como cuando la correcta aplicación del derecho comunitario puede imponerse con tal evidencia que no deje lugar a ninguna duda razonable sobre la solución de la cuestión planteada (doctrina del acto claro). 
5.-Como ya se indicó más atrás, las relaciones entre el Tribunal de Justicia como máximo intérprete del derecho de la Unión Europea y el Tribunal Constitucional como garante último de la Constitución pueden converger desde la óptica del art. 24 CE. De este precepto constitucional se deriva el derecho a un proceso con todas las garantías y una de esas garantías es la correcta aplicación del sistema de fuentes entre las que está, desde luego, el derecho de la Unión Europea. De esa manera el TC ha podido seguir manteniendo, como ya se ha indicado, que el derecho europeo no es canon de constitucionalidad y no sirve para enjuiciar en esa sede la constitucionalidad o no de una determinada ley interna, pero, al mismo tiempo, ha hecho derivar la cuestión, como acabo de decir, al plano del art. $24 \mathrm{CE}$ que podría quedar afectado si el juez ordinario no aplica las herramientas derivadas del sistema de fuentes del derecho. Y entre las cuestiones teóricamente discutibles estaría, justamente, el supuesto en el que el juez inaplica directamente una ley nacional sin plantear la cuestión de inconstitucionalidad ante el TC o la cuestión prejudicial ante el TJ de la Unión Europea por entender en este caso que se está en presencia de un «acto aclarado»o, eventualmente, de un "acto claro» cuando se trata de órganos jurisdiccionales que agotan las instancias internas y se dan los requisitos de esta elaboración jurisprudencial. Se trata, como puede fácilmente advertirse, de una cuestión muy importante, tanto desde la óptica de sus planteamientos teóricos como de su proyección práctica y que ha dado lugar a pronunciamientos judiciales contrapuestos, por lo que hay que entender que no resulta del todo cerrada.

Prescindiendo de otros antecedentes, interesa mencionar la STC 194/2006, de 19 junio, en la que el TC otorga el amparo en un caso en el que la Sala de lo contencioso-administrativo de un TSJ inaplicó una ley española por entender que era contraria al derecho de la Unión Europea sin plantear la correspondiente cuestión prejudicial al Tribunal de Luxemburgo, dado que se trataba de un supuesto similar a otro en el que ya se había pronunciado - precisamente en un caso español— el propio TJ. Es decir, el prototipo del supuesto de la doctrina del «acto aclarado». El recurrente entendía que el TSJ había incurrido en un exceso de jurisdicción al dejar de aplicar una ley vigente no afectada por la Sentencia del Tribunal de Justicia de la UE dado que la norma a propósito de la cual éste se había pronunciado (la Ley del IVA), con ser similar a la ley cuestionada, no era como tal aplicable a Canarias de acuerdo con las previsiones de la adhesión de España a la UE. Según la recurrente, la Sala, antes de inaplicar una ley postconstitucional, debería haber planteado bien la cuestión de inconstitucionalidad, bien la cuestión prejudi- 
cial (obligatoria cuando la duda se suscita ante un Tribunal que agota la vía judicial interna, como era el caso). El TC aceptó que el precepto legal declarado contrario al derecho de la UE por la Sentencia de Luxemburgo era materialmente idéntico al contemplado en el caso, pero inmediatamente afirmó que la declaración efectuada por el Tribunal de Justicia de la UE no afectaba — por la razón ya indicada - a la ley considerada $\mathrm{y}$, en consecuencia, se trataba de una disposición legal vigente que el órgano judicial no podía dejar de aplicar sin plantear o bien cuestión de inconstitucionalidad (si la entendía contraria a algún principio constitucional) o bien una cuestión prejudicial (si estimaba que la regulación establecida era contraria al derecho comunitario). Para el TC el tema, así planteado, tenía relevancia constitucional porque afectaba al sistema de fuentes e implicaba o podía implicar «la vulneración del derecho al proceso debido" y, con ello, al $24 \mathrm{CE}$. En tales condiciones estima el recurso y otorga el amparo, por más que el TC insiste en que no le corresponde resolver si existía o no la pretendida contradicción entre la normativa interna y el derecho comunitario que justificase la inaplicación de aquélla en beneficio de ésta, «sino, única y exclusivamente, si el juez español ha adoptado su decisión inaplicativa dentro de su jurisdicción, esto es, en el proceso debido y con todas las garantías».

La necesidad del planteamiento de la cuestión de inconstitucionalidad resulta incondicionada - dice el TC — en relación con las normas legales posteriores a la Constitución. Respecto a las normas posteriores a la Constitución, digo, porque en relación con las anteriores la cuestión es distinta y no plantea problemas, según precisó desde el primer momento la STC de 2 de febrero 1981, según la cual ante una norma preconstitucional contraria a la Constitución el juez puede plantear la cuestión de inconstitucionalidad, al entender que se ha producido una inconstitucionalidad sobrevenida, pero puede optar también por inaplicar la ley de que se trate al considerar que la ley posterior - la Constitución- la ha derogado. Pero en relación con las normas legales posteriores a la Constitución el Tribunal dirá que el planteamiento de la cuestión es imprescindible si no es posible mantener una interpretación de la ley cuestionada que acomode su sentido y aplicación a la Norma Suprema. Y, de otro lado, el planteamiento de la cuestión prejudicial para dejar de aplicar una norma legal vigente por su contradicción con el derecho comunitario resulta imprescindible — dice también el Tribunal Constitucional- para mantener el respeto al sistema de fuentes establecido como garantía inherente al principio de legalidad. Al dejar de aplicar el TSJ la norma interna, el TC entendió en esta Sentencia que se vulneró el sistema de fuentes relativo al control de normas. Resulta patente - 
precisa el TC_ que una Sentencia del Tribunal de Justicia de las Comunidades Europeas que declara la incompatibilidad entre la normativa nacional y una Directiva comunitaria no puede justificar la inaplicación de una ley parecida, pero diferente, y referida a un territorio en el cual no es aplicable la Directiva de la que se trataba. Tales diferencias no autorizaban, pues, al órgano judicial a inaplicar un precepto legal vigente sin acudir a los instrumentos que el ordenamiento jurídico arbitra para el control de su acomodación a la Constitución o al derecho comunitario. En consecuencia, como he dicho, otorgó el amparo.

Muy distinta es la conclusión de la STC 78/2010, de 20 octubre, que analiza exactamente el mismo supuesto y rectifica, expresamente y por decisión del Pleno del TC, la doctrina de la anterior STC 194/2006. La cuestión era, de nuevo, saber si el TSJ de Canarias había actuado correctamente al extender la doctrina sentada en una Sentencia del TJ de Luxemburgo a un caso similar, con la consecuencia práctica de que el Tribunal inaplicó él mismo una ley nacional dando prioridad al derecho de la Unión Europea. El TC comienza diciendo que la cuestión de inconstitucionalidad y la cuestión prejudicial de la Unión Europea se ajustan a exigencias diferentes. La primera es obligada en relación con normas legales posteriores a la Constitución si el juez entiende que no es posible una interpretación de esas normas acorde con la Constitución. El juez no puede, pues, por sí mismo, inaplicar una ley postconstitucional. Si duda de su constitucionalidad tiene que plantear la cuestión. Si no duda, la aplicará. Pero no puede, sin más, inaplicarla.

El régimen de la cuestión prejudicial del derecho de la UE es diferente, dice el TC. El juez no siempre está obligado a plantearla, ni siquiera - precisa- «tratándose de decisiones de órganos jurisdiccionales nacionales que no son susceptibles de un recurso judicial conforme al derecho interno». También en esos casos puede inaplicar la norma interna y no plantear la cuestión prejudicial cuando la cuestión suscitada sea materialmente idéntica a otra que haya sido objeto de una decisión prejudicial en un caso análogo (doctrina del acto aclarado) y, también, cuando la aplicabilidad del derecho comunitario sea tan evidente que no deje lugar a ninguna duda razonable (doctrina del acto claro). Así, pues, en esos casos se puede dejar de aplicar una norma legal vigente por su contradicción con el derecho europeo, es decir, cuando concurran «los presupuestos fijados al efecto por el propio derecho comunitario, cuya concurrencia corresponde apreciar a los jueces y tribunales de la jurisdicción ordinaria».

El inciso final del Fundamento Jurídico que acaba de reproducirse (es decir, que la apreciación de la concurrencia de los presupuestos fija- 
dos por el derecho comunitario corresponde a los jueces y tribunales de la jurisdicción ordinaria) parece ser —es- la clave de la diferente respuesta de esta Sentencia y la anterior 194/1996 cuyos elementos fácticos eran, sin embargo, idénticos. En efecto, en el caso que está en la base de la STC 78/2010 el Tribunal de Canarias inaplicó (como en el supuesto que dio pie a la STC 194/2006) una ley sin plantear la correspondiente cuestión prejudicial. Y en esa inaplicación se basó el recurso de amparo por entender el recurrente, como en el caso de la STC 194/2006, que se viola así el art. $24 \mathrm{CE}$. El TC, sin embargo, en esta ocasión denegará el amparo admitiendo así, indirectamente, que la inaplicación - justificada o no conforme al derecho de la Unión Europea- es una opción posible frente a la otra alternativa de la cuestión prejudicial y que esa opción corresponde analizarla y valorarla a los tribunales ordinarios y, en consecuencia, no tiene en ese caso proyección desde la óptica del art. $24 \mathrm{CE}$, que es la que le corresponde al TC analizar.

Dos posturas, pues, matizadamente diferentes acerca de la incidencia constitucional del no planteamiento de una cuestión prejudicial. Dos posturas que expresan la dificultad de sostener posiciones cerradas en un asunto como este lleno de matices y en el que las circunstancias del caso resultan importantes. De acuerdo, pues, con la doctrina de la STC 78/2010 el juez puede plantear la cuestión prejudicial si duda de la compatibilidad de la norma interna con el derecho europeo. Pero puede también, en las mismas circunstancias de duda, inaplicar la norma interna si dicha incompatibilidad es evidente (y no da lugar a ninguna duda razonable) o si se trata de una cuestión idéntica y en un caso igual ya resuelto por el TJ de Luxemburgo. Y ello aunque se trate de órganos jurisdiccionales nacionales cuyas resoluciones no sean susceptibles de recurso que son los que, conforme al art 267 TFUE, en principio, deben plantear la cuestión.

La posterior y más reciente STC 232/2015, de 5 de noviembre, ya citada, concreta un tanto la posición anterior del Tribunal y parece dar un paso más en cuanto a la vinculación de las decisiones del Tribunal de Justicia de la UE desde la perspectiva constitucional interna.

En dicha Sentencia, en efecto, el Tribunal comienza recordando, como nos consta, que el derecho de la Unión no es un canon de constitucionalidad, pero para añadir inmediatamente que eso no significa que el TC deba abstenerse de cualquier valoración cuando los poderes públicos aplican el derecho de la Unión Europea o se plantee su posible contradicción de éste con el derecho nacional. Insiste también en que su intervención ha de hacerse desde la perspectiva propia de las específicas funciones del TC, es decir, valorando si se ha ocasionado o no alguna 
vulneración a derechos fundamentales y libertades públicas cuya tutela el TC tiene encomendada, lo que derivará, normalmente, a enfocar la cuestión desde la óptica del art. 24 CE (derecho a la tutela judicial efectiva y a un proceso con todas las garantías).

Desde esos postulados, el TC reitera su doctrina anterior según la cual «dejar de aplicar una ley interna, sin plantear cuestión de inconstitucionalidad, por entender un órgano jurisdiccional que esa ley es contraria al derecho de la Unión Europea, sin plantear tampoco cuestión prejudicial ante el Tribunal de Justicia de la Unión Europea, es contrario al derecho a un proceso con todas las garantías (art. 24.2 CE) si existe una "duda objetiva, clara y terminante" sobre esa supuesta contradicción (STC 58/2004, FFJJ 9 a 14)». Si existe una "duda objetiva, clara y terminante», lo que significa, a sensu contrario, que si no existe esa duda o no tiene esas características, esto es, si la cuestión es meridianamente clara, la inaplicación es posible sin necesidad de plantear la cuestión prejudicial ni la cuestión de inconstitucionalidad.

En sentido contrario, aplicar una ley nacional supuestamente contraria al derecho de la Unión (según la parte) sin plantear la cuestión prejudicial, «no vulnera el derecho a la tutela judicial efectiva si esa decisión es fruto de una exégesis racional de la legalidad ordinaria» (así, SSTC 27/2013, de 11 febrero; 212/2014, de 18 diciembre y 99/2015, de 25 mayo). Lo que supone, también a contrario y siguiendo esa misma lógica, que sí quedaría vulnerado el derecho del art. $24 \mathrm{CE}$ si ese resultado no es el fruto de esa «exégesis racional» apuntada, lo que no es sino un argumento circular que remite, a la postre, a algo tan poco asible como saber cuál es esa "exégesis racional» determinante.

Ahora bien —añade la Sentencia 232/2015 y aquí radica quizá su pequeña novedad-, «sí corresponde a este Tribunal velar por el respeto del principio de primacía del derecho de la Unión cuando, como aquí ocurre [...], exista una interpretación auténtica efectuada por el propio Tribunal de Justicia de la Unión Europea. En estos casos, el desconocimiento y preterición de esa norma de derecho de la Unión, tal y como ha sido interpretada por el Tribunal de Justicia, puede suponer una "selección irrazonable y arbitraria de una norma aplicable al proceso”, lo cual puede dar lugar a una vulneración del derecho a la tutela judicial efectiva (STC 145/2012, de 2 julio, FFJJ 5 y 6)». Y ello porque los jueces, todos los jueces, están obligados a deducir las consecuencias pertinentes de las Sentencias del Tribunal de Justicia de la Unión y han de inaplicar las normas nacionales que se le opongan.

Se trata, en definitiva, de un problema interpretativo sumamente interesante que pivota sobre conceptos abiertos e indeterminados y que, 
sea cual sea la posición que acabe consolidándose, supone o puede suponer, en ciertos casos, pero no siempre, un cambio significativo en la posición del juez ordinario ante el derecho interno.

6.-La lenta penetración en el ámbito interno de la jurisprudencia de Luxemburgo y el proceso de adecuación y aplicación unificada del derecho de la Unión Europea ha dado recientemente un paso más con la Ley Orgánica 7/2015, de 21 julio, de reforma de la LOPJ y de la Ley de Jurisdicción Contencioso-Administrativa.

En efecto, la citada LO 7/2015 ha añadido un precepto importante, el art. 4.bis, a la citada LOPJ, con la intención de insistir en la vinculación de los jueces y tribunales españoles al derecho de la Unión Europea y a la interpretación que de él hace el Tribunal de Justicia de la UE. A estos efectos el nuevo artículo precisa, en su apartado 1, que «los jueces y tribunales aplicarán el derecho de la Unión Europea de conformidad con la jurisprudencia del Tribunal de Justicia de la Unión Europea», especificando en el apartado 2 que: "Cuando los Tribunales decidan plantear una cuestión prejudicial europea lo harán de conformidad con la jurisprudencia del Tribunal de Justicia de la Unión Europea y, en todo caso, mediante auto, previa audiencia de las partes».

El derecho europeo y la jurisprudencia que lo interpreta en última instancia adquiere así una presencia expresa y solemne que tiene su complemento en la apertura del recurso de casación a los supuestos de violación o desconocimiento del derecho de la Unión Europea.

Así, según el nuevo art. 88 de la Ley Jurisdiccional, el recurso de casación podrá ser admitido a trámite cuando la Sala del TS estime que el recurso presenta interés casacional objetivo para la formación de jurisprudencia, lo que puede considerarse que existe cuando, entre otras circunstancias, la resolución impugnada «interprete y aplique el derecho de la Unión Europea en contradicción aparente con la jurisprudencia del Tribunal de Justicia o en supuestos en que aún pueda ser exigible la intervención de éste a título prejudicial». Novedad ciertamente importante, pero de no fácil lectura e identificación (basta por ejemplo la «apariencia» de la contradicción) y que puede dar lugar a problemas de interpretación, aunque el hecho de que se trate de una circunstancia en el fondo discrecional reduce, probablemente, su potencial problemático.

Por lo demás, el art. 88.2 se refiere al derecho europeo en al menos otras dos circunstancias en las que potencialmente puede haber interés casacional. Según dicho artículo, en efecto, el interés casacional se puede dar cuando la resolución impugnada «fije, ante cuestiones sustancialmente iguales, una interpretación de las normas de derecho estatal o de la Unión Europea en las que se fundamenta el fallo contradictoria con 
la que otros órganos jurisdiccionales hayan establecido» [apartado a)] o «siente una doctrina sobre dichas normas que pueda ser gravemente dañosa para los intereses generales» [apartado b)].

El art. 93.1 precisa el contenido de la sentencia del recurso de casación que deberá fijar «la interpretación de aquellas normas estatales o la que tenga por establecida o clara de las de la Unión Europea», lo que remite, claro es, a la jurisprudencia del TJ de la Unión Europea.

7.-Por lo demás, la nueva regulación de la casación llevada a cabo en la Ley Orgánica 7/2015 puede afectar y afecta a la importante cuestión de qué tribunales pueden y cuáles deben plantear la cuestión prejudicial. Importa recordar a este respecto - aunque es cuestión ya pacífica- que los tribunales que deben plantear la cuestión prejudicial no son solamente los que, desde un punto de vista institucional y jerárquico, culminan la organización judicial sino, más sencillamente, los que, en el caso concreto considerado, deciden «en última instancia». Decidir «en última instancia» plantea, a su vez, la cuestión de los recursos y muy especialmente del recurso de casación, sobre todo, como digo, a la luz de su reciente reforma de 2015, que modifica de manera sustancial los arts. 86 a 93 de la Ley 29/1998, de la Jurisdicción Contenciosoadministrativa.

Como ya he dicho, la Ley de reforma generaliza ahora el recurso de casación frente a casi todas las Sentencias de los TSJ (art. 86.1 y 2 LJ), aunque somete la admisión efectiva del recurso a tal cúmulo de requisitos que en la práctica serán previsiblemente muy pocos los casos de los que finalmente conozca el TS. Pues bien, la citada teórica generalización afecta a la identificación del órgano jurisdiccional que no sólo puede sino que debe, en su caso, plantear la cuestión prejudicial si duda de la adecuación de una norma interna con el derecho de la Unión Europea. Si las Sentencias de los TSJ son todas o casi todas ellas, como digo, teóricamente susceptibles de casación, el TS se convierte en el órgano jurisdiccional último a efectos del art. 267 TFUE y no ya el TSJ. Por tanto, será él el órgano que debe, en su caso, plantear la cuestión despojándose así a las Salas de los TSJ de dicha obligación.

Así, pues, la nueva regulación de la casación incide en las relaciones entre el derecho interno y el derecho europeo y, en consecuencia, en el diálogo de tribunales a que antes me refería desde varias perspectivas parcialmente diferentes, como se acaba de ver.

8.-Estamos, pues, en un momento crucial, por delicado, de la construcción de Europa. Un momento de crisis política e institucional que se añade y sobrepone a un proceso previo de aumento de las competencias de la Unión Europea tras el Tratado de Lisboa que dan lugar, en 
paralelo, a una mayor presencia del derecho de la UE en la actividad de todas las Administraciones públicas y, por ende, en la conflictividad derivada de esa actividad. Y así como la crisis política e institucional precisa ideas claras, decisiones valientes y líderes reconocidos para sobreponerse a los problemas del presente y mirar con perspectiva, la crisis jurídica necesita una aplicación unificada del derecho de la Unión cuyas Administraciones son las Administraciones nacionales y cuyos tribunales son los tribunales internos, sin perjuicio del definitivo criterio del Tribunal de Luxemburgo cuya doctrina unificadora prima sobre todos ellos.

Son necesarias, pues, pautas claras para garantizar esa aplicación unificada.

La fórmula tradicional ideada para garantizar esa unificación de criterios ha sido, como en otros casos parecidos, la técnica de la cuestión prejudicial. Pero, por evidentes razones de número y cantidad, no puede esperarse que el TJ se pronuncie en cada ocasión que surge un problema interpretativo sobre él. El precio sería la lentitud de la respuesta y el colapso mismo del Tribunal. Es necesario, creo, apostar antes por algunas soluciones parciales y pragmáticas aunque sean provisionales. Apostar por el mejor y mayor conocimiento del derecho europeo, de forma que salga del tarro de las esencias exquisitas de los especialistas; apostar por la utilización en las normas de un lenguaje más comprensible y común; apostar por facilitar en el ámbito interno el acceso al recurso —en particular de casación- cuando se alegue y se razone que una sentencia viola o desconoce la jurisprudencia del TJ, es decir, interpretar con generosidad el supuesto del art. 88.2.f) de la Ley Jurisdiccional como supuesto de interés casacional; apostar, finalmente, por un mayor compromiso del Tribunal Constitucional en esa misma línea interpretativa al hilo de la jurisprudencia de Luxemburgo — como asume y aplica la de Estrasburgo- aunque sea desde la perspectiva indirecta del derecho a la tutela judicial efectiva.

En resumen, se trata de buscar un equilibrio en la actividad interconexionada de todos los Tribunales europeos. Una tarea ciertamente difícil, pero posible si hay voluntad de hallar ese equilibrio, se ponen los medios materiales y se eligen las personas apropiadas para ello.

Está en juego una idea de Europa a través del derecho. El derecho no es un fin; es un instrumento al servicio de un fin. Esta Revista y otras que destacadamente publica el mismo editor pueden jugar un papel en esa gran tarea. Cuando hace 56 años la Revista de Administración Pública inició su andadura nadie podía pensar en Europa, ni en el derecho europeo, como tampoco nadie pensaba en la Constitución o en la des- 
centralización política y administrativa que suponen las comunidades autónomas. Pero la idea de Europa poco a poco fue siendo objeto de atención académica. Si se analizan los 199 números hasta ahora publicados de la RAP se puede observar muy bien no sólo la evolución de la Revista sino la propia transformación del país. Y si al principio preocupaban unos temas poco a poco esas preocupaciones fueron cambiando y así, lentamente, pero cada vez con más fuerza, los temas europeos fueron también entrando en los contenidos de los Índices, sobre todo a partir de la segunda mitad de la década de los años ochenta del pasado siglo, precisamente cuando el derecho europeo dejó de ser visto como un derecho ajeno.

Como decía al principio de este modesto ensayo, detrás de la idea de Europa, del derecho europeo y de los tribunales que lo interpretan y sostienen hay algo mucho más importante. Hay una historia que hay que conocer, unos valores básicos conquistados con esfuerzo y tesón que hay que interiorizar, una cultura que cuando se adjetiviza está llena de sobreentendidos que debemos resaltar. Y en esa tarea, como también apuntaba al principio, destaca el trabajo de los medios de comunicación, de la escuela y del derecho y los tribunales que lo aplican. Desde la Universidad y la academia importa cultivar esas tareas. Por eso creo que resulta tan oportuna la idea del actual director de la Revista de dedicar este simbólico número 200 a reflexionar sobre diversos aspectos del derecho de la Unión Europea en el que tanto nos va. Por mi parte, me uno con gusto a esa tarea de socialización con este sencillo estudio para destacar la importante posición del juez en la función que más importa, que es la de la eficacia real y efectiva del derecho europeo que, en primera línea, ellos aplican e interpretan.

Santander, mayo de 2016 